\title{
ASPECTOS EPISTEMOLÓGICOS DO CONCEITO DE CUIDADO/CONFORTO: OBJETO DE TRABALHO E OBJETO DE CONHECIMENTO DE ENFERMAGEM*
}

Carlos Roberto Lyra da Silva', Vilma de Carvalho², Nébia Maria Almeida de Figueiredoº Teresa Tonini ${ }^{4}$

\begin{abstract}
RESUMO: Reflexão acerca de aspectos epistemológicos do cuidado e do conforto como objetos de conhecimento em Enfermagem. Ressalta-se a importância da especificidade dos objetos de conhecimento em relação à coerência no pensamento epistemológico sobre o cuidado de enfermagem e o conforto. Esses objetos apresentam-se no espaço de exterioridade - à margem de - do pensamento e do conhecimento científicos, embora o cuidado seja almejado recentemente por outras áreas de conhecimento e inserido nos imaginários coletivos, das regras do pensamento lógico, das formações discursivas, capazes de vincular valores e o saber com o pensamento e a razão na formação de enfermeiros que cuidam e/ou que investigam.

PALAVRAS-CHAVE: Enfermagem; Epistemologia; Ciência

\section{EPISTEMOLOGICAL ASPECTS OF THE CONCEPT OF CARE/COMFORT: THE OBJECT OF WORK AND THE OBJECT OF NURSING KNOWLEDGE}

\begin{abstract}
Reflection on epistemological aspects of care and comfort as objects of knowledge in Nursing. The study emphasizes the importance of specificity of objects of knowledge in relation to coherence in epistemological thinking about nursing care and comfort. These objects appear in the space of exteriority - at the edge of - scientific knowledge and thinking. However, the care may have been wished for recently in other areas of knowledge and inserted in imaginary collectives, in the rules of logical thinking, and in discursive formations, capable of linking values and knowledge with thinking and reason in the training of nurses who care or investigate.

KEYWORDS: Nursing; Epistemology; Science.

\section{ASPECTOS EPISTEMOLÓGICOS DEL CONCEPTO DE CUIDADO/CONFORTO: OBJETO DE TRABAJO Y OBJETO DE CONOCIMIENTO DE ENFERMERÍA}

RESUMEN: Reflexión acerca de aspectos epistemológicos del cuidado y del confort como objetos de conocimiento en Enfermería. Se destaca la importancia de la especificidad de los objetos de conocimiento referentes a la coherencia en el pensamiento epistemológico acerca del cuidado de enfermería y del conforto. Eses objetos se presentan en el espacio de exterioridad - a la orilla de - del pensamiento y del conocimiento científicos, a pesar de el cuidado ser objeto recientemente de otras áreas de conocimiento e inserido en los imaginarios coletivos, de las reglas del pensamiento lógico, de las formaciones discursivas, capaces de vincular valores y el saber con el pensamiento y la razón en la formación de enfermeros que cuidan y/o que investigan.

PALABRAS CLAVE: Enfermería; Epistemología; Ciencia.

\footnotetext{
*Trabalho resultante da disciplina "Para uma Epistemologia da Enfermagem" do Programa de Doutorado da Escola de Enfermagem Anna Nery da Universidade Federal do Rio de Janeiro - EEAN UFRJ.

${ }^{1}$ Enfermeiro. Doutor em Enfermagem. Professor da Escola de Enfermagem Alfredo Pinto da Universidade Federal do Estado do Rio de Janeiro - EEAP UNIRIO.

${ }^{2}$ Enfermeira. Doutora. Professora Emérita da UFRJ.

${ }^{3}$ Enfermeira. Doutora. Professora do Departamento de Enfermagem Fundamental e do Programa de Pós-Graduação da EEAP UNIRIO.

${ }^{4}$ Enfermeira. Doutora em Enfermagem. Professora do Programa de Pós-Graduação da EEAP UNIRIO.
}

\author{
Autor correspondente: \\ Carlos Roberto Lyra da Silva \\ Universidade Federal do Estado do Rio de Janeiro \\ Av. Pasteur, 296 - 22290-240 - Rio de Janeiro-RJ-Brasil \\ E-mail: cr-mano@uol.com.br
}

Recebido: $23 / 03 / 10$

Aprovado: 25/05/11 


\section{INTRODUÇÃO}

Justifica-se esta reflexão pela necessidade de buscar uma aproximação do conceito de conforto no cuidado de enfermagem como objeto real, de trabalho e de conhecimento no plano epistemológico, considerando sua capacidade de transformação e de seus efeitos na prática social, sobretudo na saúde pública, onde o cuidado ocorre e é exercitado no âmbito da intersubjetividade dos profissionais.

O conhecimento e o saber sobre a realidade decorrem a partir de diferentes atividades sociais, desde a era pré-linguística, quando a realidade surgia como um caminho que podia ser modificado pelo conhecimento, sendo este influenciado por características biológicas/ genéticas/hereditárias, assim como pelas influências culturais de grupos sociais. O conhecimento é influenciado mais intensamente pela realidade, o que, não obstante, permite a construção de seus conceitos condicionados pelas práticas sociais e sua formação idealista que perpassam pelos campos do poder e do saber, mas que no entanto, tais conceitos, não serão aqui discutidos.

Quando comparamos a Enfermagem com outras disciplinas, identificamos uma carência linguística acerca da produção de conceitos, visto que o estudo da origem e formação dos conceitos já vem sendo feito ao longo da história do pensamento filosófico e científico em diversos campos disciplinares, inclusive na área da saúde. No entanto, isso ocorre com mais restrição na área da Enfermagem e muito mais fortalecido nas áreas da Filosofia, Semântica, Psicologia, Biblioteconomia e outras.

\section{O CONCEITO NA PERSPECTIVA DE ARISTÓ- TELES E DAHLBERG}

O conhecimento científico, por si só, não é capaz de apreender de forma direta as coisas empíricas. Para tanto, faz-se necessária a aproximação de paradigmas teóricos que possam sustentar as relações fundamentais. O que está em jogo são os processos constituintes de diferentes objetos, quer sejam de trabalho ou de conhecimento. Daí a importância dos conceitos.

É preciso destacar que o conceito não é um "mero" significante como os demais. Ele é formado por três elementos, a saber: o referente, as características e a forma verbal. O processo de determinação do conceito se dá no momento em que selecionamos, na pesquisa, um item de referência - o referente ${ }^{(1)}$.
Quando nos aproximamos de um conceito acerca de um dado referente - aqui, cuidado e conforto em Enfermagem - nos é possível uma articulação com outros conceitos que constituem uma teoria científica, não pelo fato da externalidade da ciência à ideologia, mas pela estreita relação da articulação conceitual com o objeto real, por meio do objeto de conhecimento de uma determinada ciência ou, como no caso da Enfermagem, uma ciência em vias de se fazer ${ }^{(2)}$.

Falta-nos, ainda, uma cultura que valorize o pensamento conceitual em nossas ações de cuidar e, principalmente, de investigar, visto que a partir desse pensamento se consegue estabelecer as relações fundamentais do objeto real; já que o objeto de trabalho - aqui entendido como o conhecimento técnico no plano da ação - permitirá a apropriação da produtividade assistencial de acordo com nossas expectativas ideológicas. Todavia, tanto o objeto real quanto o de trabalho se correlacionam, ou seja, o objeto real emerge do objeto de trabalho. Cabe a ênfase de que é o objeto quem determina o sujeito ${ }^{(3)}$ no plano da investigação.

Considerando a jovialidade da Enfermagem como disciplina/conhecimento, seus saltos ainda estão intimamente ligados ao seu fazer ${ }^{(4)}$, carecendo de um espírito mais questionador que possa, por meio da produção de conhecimento, buscar evidências de que o cuidado e o conforto, além de objetos de trabalho, são também objetos reais e de conhecimento capazes de contribuir para construção de uma Enfermagemciência.

A produção de conhecimento científico não é um campo neutro no qual são possíveis combinações de ideias e noções, ou ainda, a convergência de teorias em prol da apreensão do objeto. Na medida que novos conhecimentos são produzidos, a realidade sofre influências e se transforma. Na Enfermagem não é diferente, a exemplo dos avanços tecnológicos que vêm a muito tempo influenciando a sua prática, principalmente quando o que está em jogo é o cuidado de alta complexidade.

Muito pelo contrário, o efeito de um conhecimento teórico é produto da articulação interna de seus conceitos, os quais, pela ação própria, não se acoplam ou desacoplam do investigador. Nesse momento, a esfera subjetiva é ativa a partir de necessidades técnicas ou talvez ideológicas em que o sujeito faz os devidos "ajustes" ou "reformulações" conceituais de acordo com a realidade empírica. Em outras palavras, compreendemos que os objetos Cuidado e Conforto em questão dividem o mesmo "solo epistemológico" - a 
Enfermagem. Mas, no entanto, não são sinonímias, e sim termos polissêmicos que, muitas vezes, têm sido utilizados na ação e na investigação de forma equivocada, talvez pelo fato de serem entendidos como sinônimos. É evidente que nem todo cuidado prestado é um cuidado que por si e em si são confortantes ou confortáveis; basta exemplificar com o momento da aspiração traqueal de um cliente acordado e lúcido. Do ponto de vista biológico, trata-se de um cuidado fundamental para a manutenção da vida do cliente, entretanto, não podemos dizer que se trata de um cuidado isento de desconforto.

Talvez este seja um dos motivos pelo qual o saber da Enfermagem esteja à margem do núcleo da racionalidade científica hegemônica, impulsionado por uma força centrífuga que o direciona para fora, que obstaculiza sua entrada no núcleo das ciências duras e entendidas como objetivas, e assim, impedindo seu reconhecimento intersubjetivo. Por isso, a preocupação em refletir sobre como é possível a Enfermagem possuir algumas dezenas de teorias explicativas sem que os sujeitos nela implicados as utilizem quantitativamente em seus ensaios (co)relacionando, (re)formulando e testando seus conceitos. Cabe a ressalva que a articulação dos conceitos de uma teoria é o caminho da concretude do pensamento.

Ademais, necessária se faz a experimentação como caminho para a verificação da teoria, com vistas à confirmação, ou não, do conceito (re)formulado com o objeto real. Não obstante, há de se fazer valer que as ciências já construídas pela especificidade de seus objetos e a (co)relação de seus conceitos já consagrados não devem ser mirados como acabados/terminados. Eles devem ser entendidos como processos não terminativos da produção do conhecimento.

Pensamos que um dos possíveis caminhos para maturação do espírito científico ${ }^{(5)}$ na Enfermagem é não se contentar com essa exteriorização a qual se encontram seus objetos; é caminhar rumo à confirmação de objetos reais - cuidado e conforto, a partir da sua argumentação, quer seja com base no racionalismo crítico; a partir de seus saltos epistêmicos, na arqueologia do saber e na configuração das estratégias que envolvem poder no saber. Para tanto, devemos elucidar a coerência epistemológica dos objetos em questão, tornando-os um foco ardente de reflexão crítica $^{(4)}$, ocupando diante da racionalidade das ciências novas formas de expressão no diálogo que se estabelece com outros saberes.

Devemos pensar que esses dois objetos reais de conhecimento são, também, de prática; são objetos positivos que podem, sem dúvida alguma, complementar os paradigmas do modelo biomédico que ignoram as relações ecológicas e a complexidade do ser humano. Tanto na ação quanto na investigação, entendemos cuidado e conforto como fundamentais para o conhecimento de Enfermagem. Como objetos reais/trabalho e conhecimento, eles permitem o diálogo entre os mais diversos saberes, abrindo uma via de compreensão da realidade a partir de diferentes pontos de vista; e são capazes de estreitar um diálogo coletivo diferentemente e para além de objetos fragmentados do conhecimento.

Falar de uma epistemologia do cuidado e do conforto é transcender o exercício permanente de reflexão, tentativas de teorização e ações concretas, potencialmente transformadoras e construtoras de uma realidade comprometida com mudanças na representação da realidade; convocando diferentes disciplinas com diferentes visões de mundo.

A articulação e as conexões entre os objetos em questão, nas mais diferentes ciências, fortalece o entendimento de que ao não pertencer ao objeto de conhecimento de nenhuma das ciências não implica a inclusão dos seus efeitos nos campos de saberes, mas pode corroborar com a articulação de seus conceitos.

A articulação de um mesmo conceito ou de seus efeitos entre as ciências, ainda que não co-habitem a mesma área de conhecimento, pode ser exequível, desde que devidamente aplicado teoricamente. Um exemplo disso é a articulação do conceito de diagnóstico na Medicina, na Enfermagem, na Odontologia, ou ainda, na Engenharia. Há de se compreender que tal articulação e seus efeitos não significam a existência de relações de poder dominador de uma sobre a outra, ou ainda, afirmação de que uma ciência em vias-dese-fazer é nada mais - e nada menos - que um "ramo" ou "território" de outra já edificada/dominante, há de se resguardar as suas especificidades.

\section{CARACTERÍSTICAS CONCEITUAIS INTRÍN- SECAS E EXTRÍNSECAS: CUIDADO E CON- FORTO}

Forma, cor, tamanho, peso, por exemplo, podem caracterizar um objeto - referente em si mesmo, sem relação com outros. Essas são as características intrínsecas. Assim, é próprio de uma vigia de navio ser redonda, de uma janela de navio ser retangular; ou das pedras preciosas terem cor, brilho e facetas lapidadas; estas são apenas características que não modificam a natureza do 
objeto. Uma cadeira tem como natureza a possibilidade de assento, independente se é construída de madeira, ferro, plástico ou se da cor vermelha, preta ou branca, contudo, jamais deixará de ser cadeira.

Quando um referente se caracteriza por ter uma função (peculiar) que um outro não tem, ou uma finalidade (precípua) que um outro não tem, ou por apresentar componentes diferentes de outros referentes semelhantes, se diz que estas características são intrínsecas. Ou seja, elas são identificadas num objeto em relação ao outro. Esta ideia se aplica também aos objetos cuidado e o conforto. Entretanto, quando este referente vem acompanhado de algumas peculiaridades, ainda que suas funções se aproximem ou se igualem, ele continua mantendo as propriedades que lhe são inerentes, principalmente para predicar seus atributos - cuidado de enfermagem que pode promover conforto.

Articulação de objetos, conceitos ou ainda das ciências não se limita a uma práxis transdisciplinar. Ela resulta na importação de paradigmas e/ou na aplicabilidade de objetos reais de uma determinada abrangência do conhecimento ao outro, haja vista a emergência de outras disciplinas se auto-intitularem "operadoras do cuidado". Diferentemente do objeto de tralho, o objeto real de cada ciência é dotado de especificidades que o torna intransferível e inaplicável. Nesse sentido, conforto como produto resultante do cuidado de enfermagem é objeto real da Enfermagem.

\section{CONSIDERAÇÕES FINAIS}

Com base no exposto, cumpre-nos considerar, por último e não por fim, a necessidade imperiosa de aquecimento do processo de construção científica na Enfermagem em seu caráter quantitativo e, principalmente, qualitativo. Sobretudo, no que diz respeito à produção conceitual em Enfermagem com vistas à emergência de conceitos que possam contribuir para a diminuição da polissemia em Enfermagem. Faz-se necessário acusar que nossa aventura e ousadia epistemológica não estão assentadas apenas em sua unidade temática, mas no lugar do saber da Enfermagem. O cuidado de enfermagem e o conforto, assim como o físico e o biológico como objetos real, de trabalho e de conhecimento são em si e por si autônomos e não conferem tão somente com o caráter formativo de uma hierarquia fundada em sua gênese histórica, mesmo considerando sua importância no contexto da investigação científica.

Não foi e nem é intenção que a opinião balizada, aqui exarada acerca de os objetos - cuidado e conforto como objetos de conhecimento em enfermagem, seja entendida como um imperativo categórico, muito menos, tomada como cânone científico. Porém, buscamos tão somente, compartilhar com os leitores, uma apreciação de natureza crítica e filosófica, uma contribuição para um plano de discussão em torno de uma questão em aberto e não como um ponto de vista assentado sob a ótica do dever ser.

Para nós, a tentativa de enquadramento epistemológico do cuidado e conforto como objetos específicos da Enfermagem se manifesta em um desejo e uma necessidade infinita de saber, tal como um sol que não gosta de brilhar sempre no mesmo zênite e ao olhar para o horizonte ao entardecer se oculta de sua própria luz no lado escuro do mundo, que pisca o olho um pouco mais inclinado para o sul que para o norte; que gosta de variar seus acasos, ao sabor das estações, pintando os céus com desenhos, cores e luzes cambiantes; que gira a cada noite para reaparecer em um novo dia.

\section{REFERÊNCIAS}

1. Dahlberg I. A referent-oriented analytical concept theory of interconcept. International Classification. 1978;5(3):42-150.

2. Carvalho V. Cuidando, pesquisando e ensinando: acerca de significados e implicações para a prática da enfermagem. Rev Latino-Am Enfermagem. 2004;12(5):806-15.

3. Hessen J. Teoria do conhecimento. São Paulo: Martins Fontes; 2003.

4. Silva, CRL, Carvalho, V. Figueiredo, NMA. Aspectos epistemológicos do cuidado e conforto como objetos de conhecimento em enfermagem. Cogitare Enferm. 2009;14(4):769-72.

5. A formação do espírito científico. Trad. de Estela dos Santos Abreu. Rio de Janeiro: Contratempo; 2007. 